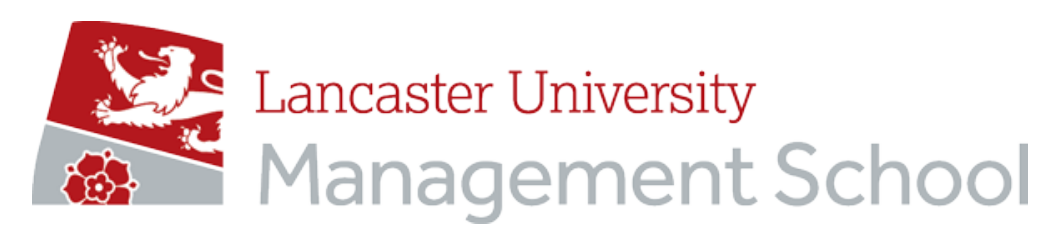

Economics Working Paper Series

2016/012

\title{
Indivisibilities in the Ricardian model of trade
}

\author{
Kwok Tong Soo \\ The Department of Economics \\ Lancaster University Management School \\ Lancaster LA1 4YX \\ UK \\ provided that full acknowledgement is given.
}




\title{
Indivisibilities in the Ricardian model of trade
}

\author{
Kwok Tong Soo* \\ Lancaster University
}

September 2016

\begin{abstract}
This paper develops a Ricardian model of trade in which there are indivisibilities in both production and consumption. Indivisibilities give rise to new results compared to the standard model with perfectly divisible production and consumption. Production indivisibility may result in complete specialisation even in autarky, while consumption indivisibility may result in consumption heterogeneity even amongst ex ante identical consumers. Indivisibilities lead to efficiency losses relative to the perfectly divisible case.
\end{abstract}

JEL Classification: F11.

Keywords: Ricardian model; CES preferences; indivisible production; indivisible consumption. * Department of Economics, Lancaster University Management School, Lancaster LA1 4YX, United
Kingdom. Tel: $+44(0) 1524$ 594418. Email: k.soo@lancaster.ac.uk 


\section{Introduction}

This paper is about indivisibilities. Conventional economic analysis often assumes that goods and services are perfectly divisible. However, this may not be true in reality. On the consumption side, consumers can buy one unit of a good, or two units. But they usually cannot buy 1.52 units. Similarly, on the production side, a firm may set up a production facility that produces a certain level of output. To increase production, the firm may choose to set up a second production facility. But it often cannot, without difficulty, alter its output in a marginal way, beyond its capacity constraint. This of course is related to the concept of the minimum efficient scale in the industrial organisation literature.

It is easy to make the mistake of thinking that indivisibility is important only at the individual level, and that it disappears in a large economy with millions of firms and consumers. Yet a moment's thought shows that the implications of indivisibility hold true irrespective of whether there are two or two million people in the economy. For instance, if there are two million identical consumers, and one million units of a particular indivisible good, then despite the fact that the consumers are identical, one million consumers will consume one unit of the good, while the other million consumers will consume none of the good.

This paper develops a simple Ricardian model of international trade to analyse the effects of indivisibilities on both the production and consumption sides on the results of the model. It turns out that there are indeed large implications. If the conventional constant elasticity of substitution (CES) utility function is assumed, then production indivisibility implies that a country may be completely specialised in its comparative advantage good, in autarky. On the other hand, consumption indivisibility implies that ex ante identical consumers may, as suggested above, end up consuming different bundles of goods especially when international trade is allowed. This then has implications for the model's predictions on the volume of trade. Combining indivisibilities in both production and consumption yields additional insights. In particular, under certain conditions, having both types of indivisibilities is identical to having only consumption indivisibility. If these conditions do not hold, then the possibility also arises of heterogeneity in consumption in autarky.

That CES preferences are assumed is going to be key in the analysis, especially for production indivisibility. Bhagwati (1967) showed that the proof of the theorem of 
comparative advantage depends crucially on assumptions on consumer preferences. That there may be limits to the division of labour has been shown in several papers. Becker and Murphy (1992) showed that coordination costs may limit the gains from the division of labour. Related analyses can be found in Sobel (1992) and Kremer (1993), and in an international dimension in Francois (1990a, 1990b). Krishna and Yavas (2005) introduce consumption indivisibilities in a transition economy. To the best of our knowledge, none of this previous literature has directly addressed the implications of indivisibility in a standard trade model.

Also related is the large literature on international trade under external increasing returns (see especially the surveys by Helpman (1984), Helpman and Krugman (1985) Chapter 3, and Choi and Yu (2003)). In particular, Helpman and Krugman (1985) show that, to replicate the integrated equilibrium, production of the sector subject to (national) increasing returns must be concentrated in a single country; in other words, it is indivisible. Here, we address indivisibility in production directly, and also consider the implications of indivisibility in consumption.

This paper is perhaps closest in its approach to Cheng et al (2000), who introduce transaction costs into the Ricardian model, adopting an "infra-marginal" approach which is similar to ours. Cheng et al (2000) define the "infra-marginal" approach as combining the marginal approach with total cost-benefit analysis, and enables the analysis of models with discontinuous jumps in the endogenous variables. Similarly, in the present paper, the presence of indivisibilities means that analysing the model through direct comparison between alternative outcomes may be a more appropriate solution method than conventional marginal analysis. Nevertheless, the issues we address in this paper are different from those addressed in Cheng et al (2000).

The next section develops the standard Ricardian model, which will serve as the benchmark for the remainder of the analysis. Section 3 considers indivisible production while Section 4 considers indivisible consumption. Section 5 combines both types of indivisibilities, while Section 6 provides some concluding comments.

\section{The model: Preliminaries}

In this section we develop the standard Ricardian model of trade as the basis for our analysis of indivisibilities. There are two countries, Home and Foreign, and two goods, 1 and 2. Each good is produced under perfect competition using labour as the 
only factor of production. There are two workers in each country who share the same technology. Production technologies take the following form:

$$
\begin{array}{lll}
\text { Home: } & Q_{1 H}=A L_{1 H} & Q_{2 H}=L_{2 H} \\
\text { Foreign: } & Q_{1 F}=L_{1 F} & Q_{2 F}=A L_{2 F}
\end{array}
$$

Where $A>1$ represents Home's comparative advantage in good 1 and Foreign's in good 2 , and is assumed for simplicity to be identical between the two countries ${ }^{1}$.

Preferences take the following constant elasticity of substitution (CES) form (where lower case letters denote per capita values, which will prove useful later):

$$
u=\left[c_{1}^{\theta}+c_{2}^{\theta}\right]^{1 / \theta}, \quad 0<\theta<1
$$

We shall perform the analysis for the Home country; outcomes for the Foreign country are analogous. First consider the case of autarky. From the consumer's first order conditions and the zero profit conditions we have:

$$
\frac{P_{1 H}}{P_{2 H}}=\frac{1}{A}=\left(\frac{c_{1 H}}{c_{2 H}}\right)^{\theta-1}
$$

Since total consumption of each good equals production in autarky, substituting from the production functions in equation (1) enables us to write down the relationship between the labour used in both goods:

$$
L_{2 H}=L_{1 H} A^{\frac{\theta}{\theta-1}}
$$

Substituting into the labour market clearing condition $L_{1 H}+L_{2 H}=L_{H}$, making use of the production functions (1) again, and noting that there are two workers/consumers in the country, gives per capita consumption of the two goods:

$$
c_{1 H}=\frac{1}{2} A L_{H}\left[1+A^{\frac{\theta}{\theta-1}}\right]^{-1}, \quad c_{2 H}=\frac{1}{2} A^{\frac{\theta}{\theta-1}} L_{H}\left[1+A^{\frac{\theta}{\theta-1}}\right]^{-1}
$$

Substituting these into the utility function (3) and simplifying gives Home's per capita utility under autarky:

$$
u_{H}^{A}=A\left(1+A^{\frac{\theta}{\theta-1}}\right)^{\frac{1-\theta}{\theta}}
$$

In free trade, each country will be specialised in its comparative advantage good, and export it to the other country in exchange for the other good. Hence, since we assume $A>1$, and since the two countries have symmetric technologies and are identical in size, the per capita free trade utility level is:

$$
u_{H}^{F T}=\left[2\left(\frac{A}{2}\right)^{\theta}\right]^{1 / \theta}=2^{\frac{1-\theta}{\theta}} A
$$

\footnotetext{
${ }^{1}$ Here, as elsewhere in the paper, the use of simple functional forms has no effect on the qualitative results of the model, unless otherwise stated.
} 
Comparing equations (7) and (8), there are gains from trade; $U_{H}^{F T}>U_{H}^{A}$. Note as well the pattern of trade: each country will export the good in which it has a comparative advantage, and since the two countries are symmetric, each country will export half of its output, and the volume of trade (exports plus imports) is:

$$
V T=2 A
$$

In the sections below, unless otherwise stated, we will make use of the assumption that $A=3$; this makes the paper's argument more transparent. If in addition we assume that $\theta=0.7$, we can obtain numerical solutions to consumption and utility levels in both autarky and free trade (recall except for the volume of trade these are per capita values):

$$
\begin{aligned}
& c_{1 H}^{A}=2.785 \\
& c_{2 H}^{A}=0.0715 \\
& u_{H}^{A}=3.097 \\
& c_{1 H}^{F T}=c_{2 H}^{F T}=1.5 \\
& V T=6 \\
& u_{H}^{F T}=4.038
\end{aligned}
$$

These values will serve as useful benchmarks to compare with the results with indivisibilities.

\section{Indivisible production}

In this section we make one major change to the model in Section 2: the two workers in each country can each produce only one of the two goods. Hence there are three possible production structures for each country: (1) both workers produce good $1 ;(2)$ both workers produce good 2; (3) one worker produces good 1 and the other worker produces good 2 .

Consider the case of the Home country in autarky (the case of the Foreign country follows analogously). Since Home has a comparative advantage in good 1, there are two possible production structures: (1) and (3) above (possibility (2) is strictly dominated by possibility (1)).

If Home is specialised in good 1 in autarky, then we have:

$$
\begin{gathered}
Q_{1 H}=2 A, \quad A, \quad Q_{2 H}=c_{2 H}=0 \\
u_{1}=A
\end{gathered}
$$

If Home produces both goods in autarky, then we have:

$$
\begin{gathered}
Q_{1 H}=A, \quad c_{1 H}=\frac{A}{2}, \quad Q_{2 H}=1, \quad c_{2 H}=\frac{1}{2} \\
u_{2}=\left[\left(\frac{A}{2}\right)^{\theta}+\left(\frac{1}{2}\right)^{\theta}\right]^{1 / \theta}
\end{gathered}
$$


Note that, regardless of the pattern of specialisation, the utility levels under autarky with indivisible labour are always lower than when there are no indivisibilities in equation (7). That is, the indivisibility leads to a loss of efficiency in the economy. Now, $u_{1}>u_{2}$ if Assumption 1 holds:

Assumption 1: $A>\left(2^{\theta}-1\right)^{-(1 / \theta)}$.

This will be true provided the technology parameter $A$ or the elasticity of substitution between goods $\theta$ is sufficiently large. That is, the labour productivity in the two goods is sufficiently different from each other, and/or the two goods are sufficiently substitutable in consumption. We assume that Assumption 1 holds for the remainder of this paper. This gives our first main result:

Proposition 1: If Assumption 1 holds, a country will be specialised in its comparative advantage good in autarky.

This result is new, since in the standard Ricardian model without indivisibilities in Section 2, in autarky a country will always produce both goods. When the country opens up to international trade, it will remain specialised in its comparative advantage good, and export it to the other country in exchange for the other good. Hence the free trade utility level remains as in equation (8) above with perfectly divisible workers. Because the indivisibility is on the production side, international trade eliminates the inefficiency caused by indivisibility.

Note as well that the source of the gains from trade is different from the traditional case. Here, the source of the gains from trade is that trade allows consumers in a country to consume both goods, compared to autarky in which they can only consume one good. In this sense the model is similar to the new trade theory of Krugman (1980), in which the gains from trade arise because trade allows consumers to consume a larger variety of goods than in autarky. We state this as Proposition 2:

Proposition 2: If Assumption 1 holds, the gains from trade arise because trade enables consumers to consume more types of goods than in autarky.

An important corollary of Propositions 1 and 2 is that there is no change in the production structure when moving from autarky to free trade. Hence, no workers suffer even temporary unemployment as a result of trade liberalisation, and everyone 
in the economy gains from free $\operatorname{trade}^{2}$. In addition, if it is indeed the case in reality that a big part of the gains from trade arise from increasing product variety (see Broda and Weinstein (2006) for evidence in the case of the United States), then this model provides an explanation of this from a Ricardian perspective.

Figure 1: The autarkic and free trade equilibria for Home when Assumption 1 holds.

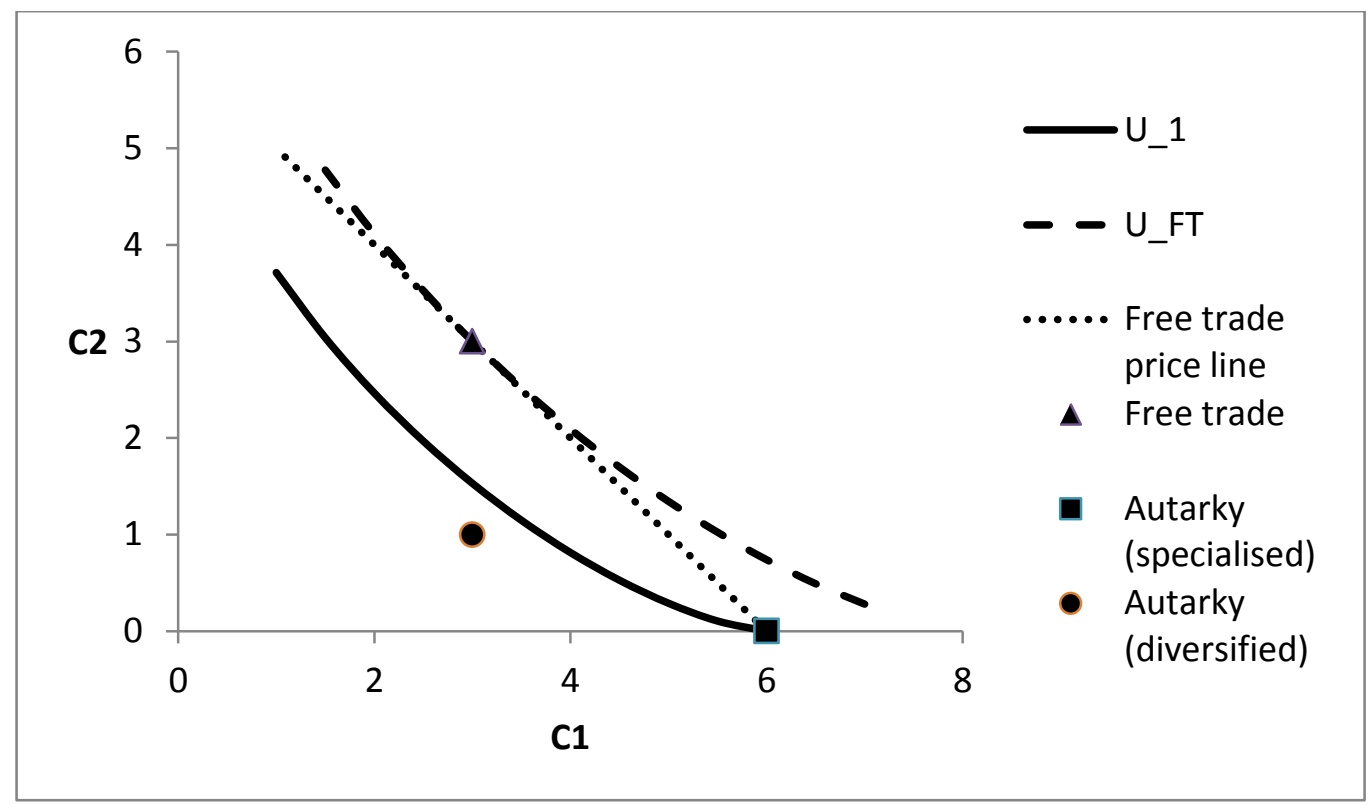

An example of Proposition 1 is shown in Figure 1 for the Home country, where it is assumed that $A=3$, and $\theta=0.7$ (as in Section 2 above). Two indifference curves are drawn, one for autarky and one for free trade (national welfare is the sum of individual utility). The country obtains higher utility under autarky when it is completely specialised in its comparative advantage good than when it is diversified (produces both goods). Similarly, it obtains higher utility under free trade than under autarky. Note that there is no production possibility frontier, since the country cannot produce intermediate amounts of the two goods (workers cannot multi-task). Hence intermediate points between the diversified and specialised autarky points are not in the country's (autarkic) feasible set. There is however a free trade price line, along which the country can trade with the other country.

Numerically, given $A=3$ and $\theta=0.7$, we obtain the following values for consumption and utility in per capita terms under autarky with indivisible workers:

$$
\text { Specialised in good 1: } \quad c_{1 H}=3 \quad c_{2 H}=0 \quad u_{1}=3
$$

\footnotetext{
${ }^{2}$ However, see the Appendix for how the results may change if we make different assumptions about labour productivity in the production functions.
} 


$$
\text { Diversified production: } \quad c_{1 H}=1.5 \quad c_{2 H}=0.5 \quad u_{2}=2.58
$$

Hence, as shown in Figure 1, being specialised in good 1 yields a higher level of utility than being diversified, for the parameter values chosen. Also, as has been noted above, comparing these values to those of the standard model in equations (10) and (11), production indivisibility leads to a welfare loss in autarky, but not in free trade.

More generally, as illustrated in Figure 1, Proposition 1 arises because, with the CES utility function, the consumer can get positive utility even when he does not consume one of the two goods. We can rewrite the utility function as:

$$
c_{2 H}=\left(u_{H}^{\theta}-c_{1 H}^{\theta}\right)^{1 / \theta}
$$

So if $c_{2 H}=0$, it must be that $u_{H}=c_{1 H}$. This contrasts with the case of CobbDouglas utility where the consumer must consume positive amounts of both goods in order to get any utility, so complete specialisation under autarky is never a feasible outcome.

\section{Indivisible consumption}

In this section we restore divisibility of production, but introduce instead indivisible consumption. That is, suppose that one of the two goods is indivisible in consumption; without loss of generality, let this be good 1. As before, we analyse the Home country; this time, we drop the country subscript to simplify notation. Consider first the case of autarky. Since the two workers/consumers are identical, utility maximisation results in both consumers seeking to consume the same bundle of goods. Since consumption of good 1 can take on only natural values, to solve for the autarkic equilibrium, start from the equilibrium without indivisibilities; then compare the utility obtainable from the two natural values of $c_{1}$ on either side of this equilibrium ${ }^{3}$.

Define a floor function $\lfloor x\rfloor$ as the largest integer less than or equal to $x$, and a ceiling function $\lceil x\rceil$ as the smallest integer greater than or equal to $x$. Then, in general, letting the subscript $N I$ stand for no indivisibilities and $I C$ for indivisible consumption, we have:

\footnotetext{
${ }^{3}$ A natural number $\mathbb{N}_{0}$ is defined as a non-negative integer. Note that we cannot simply use the nearest integer function to obtain the equilibrium, since the marginal utility of consumption may be different between the two goods.
} 


$$
\begin{gathered}
\left(c_{1}^{A}\right)_{I C} \in \mathbb{N}_{0} \quad \text { such that } \quad\left(c_{1}^{A}\right)_{I C}=\left\lfloor\left(c_{1}^{A}\right)_{N I}\right\rfloor \text { or } \quad\left(c_{1}^{A}\right)_{I C}=\left\lceil\left(c_{1}^{A}\right)_{N I}\right\rceil \\
\left(c_{2}^{A}\right)_{I C}=1-\left[\frac{\left(c_{1}^{A}\right)_{I C}}{A}\right] \\
\left(u^{A}\right)_{I C}=\max \left\{\left[\left(c_{1}^{A}\right)_{I C}\right]^{\theta}+\left[\frac{A-\left(c_{1}^{A}\right)_{I C}}{A}\right]^{\theta}\right\}^{1 / \theta}
\end{gathered}
$$

Suppose as in the previous sections that $A=3$ and $\theta=0.7$. From equation (10), the optimal per capita consumption of good 1 without indivisibilities is $\left(c_{1}^{A}\right)_{N I}=2.785$. Hence when good 1 is indivisible, the two consumers may each choose to consume either 2 or 3 units of good 1 . Consuming 2 units of good 1 yields $u_{c_{1}=2}=2.86$, while consuming 3 units of good 1 yields $u_{c_{1}=3}=3$; hence in this case the autarkic equilibrium exhibits complete specialisation in the comparative advantage good, as in the case with indivisible production ${ }^{4}$. Also similarly to the case of indivisibilities in production, in autarky indivisibilities in consumption lead to loss of efficiency relative to the perfectly divisible case, since consumers are restricted in the bundle of goods which they are able to consume. The question is, does international trade remove the inefficiency as in the case of production indivisibilities?

It turns out not to be the case. Given the structure of the model, both countries are specialised in their respective comparative advantage goods in free trade. Since we assume $A=3,6$ units of each good will be produced in the world economy. However, there are 4 consumers, so if good 1 is indivisible in consumption, two of the four consumers will consume 1 unit of good 1, while the other two consumers will consume 2 units. Conversely, the consumers who have consumed 1 unit of good 1 will consume 2 units of good 2, since goods prices are the same and all consumers have the same income level. Without adding additional structure to the model there is no way to determine which consumers consume which bundle of goods. Thus it is possible that the two Foreign consumers together consume 4 units of the Homeproduced good 1 , so that the total volume of trade is 8 units - more than the volume of trade with perfectly divisible goods and workers. Of course it is equally possible that the two Foreign consumers together consume only 2 units of good 1, so that the total volume of trade is only 4 units. Since the utility obtained from consuming

\footnotetext{
${ }^{4}$ This implies that we are comparing national consumption of good 1 of 4 units versus 6 units. One might be tempted to include a national consumption of 5 units of good 1 in the comparison. However, with indivisible consumption, national consumption of 5 units implies that one consumer consumes 3 units, while the other consumes 2 units, and it is shown in the text that consuming 3 units gives each consumer higher utility than consuming 2 units. This discussion emphasises the importance of focussing on per capita consumption and utility.
} 
either bundle of goods is the same, in the presence of even very small trade costs, the latter outcome becomes the unique, utility-maximising solution.

If $\theta=0.7$, per capita utility in free trade is 3.969 , which is less than utility with perfect divisibility; because the consumption indivisibility retains its bite in the presence of international trade, opening up the country to international trade does not eliminate the inefficiency associated with the indivisibility. Hence we can state:

Proposition 3: When there is indivisibility in the consumption of goods:

(a) In the free trade equilibrium there may be heterogeneity in consumption and uncertainty in the volume of trade.

(b) International trade does not eliminate the inefficiency caused by consumption indivisibility.

Note that the heterogeneity in consumption in Proposition 3(a) arises because we have chosen $A=3$; in general any value of $A$ such that the output of the indivisible good, when divided by the number of consumers, does not yield an integer value, will generate this heterogeneity. On the other hand, both here and in the next section, values of $A$ which generate integer values when output is divided by the number of consumers, will not result in consumption heterogeneity, since this implies that all consumers can consume the same bundle of goods despite the indivisibility.

\section{Indivisible production and indivisible consumption}

In this section we combine indivisibilities on both the consumption and production sides. Intuitively, since both types of indivisibility lead to inefficiencies, the combination of both should lead to even more inefficiencies. This intuition turns out to be true only in some cases; in other cases, consumption indivisibility appears to dominate the proceedings, with no additional impact of production indivisibility.

Start again with the case of autarky. Assume as before that both indivisibilities affect only good 1 . On the production side, if Assumption 1 holds, then the Home economy specialises in its comparative advantage good 1, produces 6 units of the good since we assume $A=3$, and each consumer consumes 3 units, obtaining utility equal to 3 . On the other hand, if Assumption 1 does not hold, then Home will produce 3 units of good 1 and 1 unit of good 2. Good 2 is perfectly divisible in consumption. However, good 1 is not; the 3 units produced have to be divided between the two consumers, so one consumer will consume 2 units while the other 
will consume 1 unit. Therefore, if Assumption 1 does not hold, we may obtain heterogeneity in consumption across ex ante identical consumers even in autarky. This result is new, since in Section 4 above, with only consumption indivisibility, the possibility of consumption heterogeneity in equilibrium arises only when there is international trade. As in Section 4, consumption heterogeneity is possible because we have chosen a value of $A$ which does not yield an integer value when the output of the indivisible good 1 is divided by the number of consumers.

Next, consider international trade. Again each country will be specialised in its comparative advantage good. We get the same outcome as in Section 4 above: consumption may be heterogeneous even though consumers are identical ex ante. The results with both indivisible consumption and production are summarised by Proposition 4:

Proposition 4: When there is indivisibility in both the production and consumption of goods:

(a) In autarky, if Assumption 1 holds, the country will be specialised in its comparative advantage good, and consumption will be identical across consumers.

(b) In autarky, if Assumption 1 does not hold, the country will produce both goods, and there may be consumption heterogeneity across consumers.

(c) In free trade, the results are identical to those in Proposition 3.

Hence, when Assumption 1 holds, having indivisibility in both production and consumption is identical to having indivisibility in consumption alone. However, if Assumption 1 does not hold, then having both types of indivisibility may increase the degree of inefficiency in autarky relative to having only one type of indivisibility ${ }^{5}$. When international trade is allowed, the outcome collapses to that with indivisibility in consumption alone. So once again we can see that international trade can eliminate the inefficiency which arises from indivisibility in production, but not that which arises from indivisibility in consumption.

\section{Conclusions}

In this paper we have extended the standard Ricardian model of trade to consider the implications of indivisibilities in both production and consumption of goods. It

\footnotetext{
${ }^{5}$ We have resisted the temptation to obtain numerical values for the case where Assumption 1 does not hold, since these values would not be directly comparable to the values in previous sections.
} 
turns out that such indivisibilities have large effects on the outcomes of the model. Indivisibilities in production may give rise to complete specialisation even in autarky, while indivisibilities in consumption may give rise to consumption heterogeneity among ex ante identical consumers. Both forms of indivisibility lead to inefficiencies and lower welfare levels relative to the perfectly divisible case. International trade eliminates the inefficiency from production indivisibility, but not that from consumption indivisibility.

The model developed in this paper is very special, and we have made specific assumptions regarding parameter values to clarify the analysis. Nevertheless, we believe the main results should hold in more general situations. As noted in the Introduction, most industries have a minimum efficient scale, and most products cannot be bought in perfectly divisible quantities. What this paper has done is to show how we can analyse the implications of these indivisibilities in a simple model of international trade. Future work will consider refinements and generalisations of the model. 


\section{References}

Becker, G., Murphy, K.M., 1992. The division of labor, coordination costs, and knowledge. Quarterly Journal of Economics 107(4), 1137-1160.

Bhagwati, J., 1967. The proofs of the theorems on comparative advantage. Economic Journal $77(305)$, 75-83.

Broda, C., Weinstein, D.E., 2006. Globalization and the gains from variety. Quarterly Journal of Economics 121(2), 541-585.

Cheng. W., Sachs, J., Yang, X. 2000. An inframarginal analysis of the Ricardian model. Review of International Economics 8(2), 208-220.

Choi, J.-Y., Yu, E.S.H., 2003. External economies in the international trade theory: A survey, in Choi, E.K., Harrigan, J. (eds.) Handbook of International Trade. Blackwell Publishing, 186-212.

Francois, J.F., 1990a. Trade in producer services and returns due to specialization under monopolistic competition. Canadian Journal of Economics 23(1), 109-124.

Francois, J.F., 1990b. Producer services, scale, and the division of labor. Oxford Economic Papers 42(4), 715-729.

Helpman, E., 1984. Increasing returns, imperfect markets, and trade theory. In Jones, R.W., Kenen, P.B. (eds.), Handbook of International Economics, Volume 1, 325-365.

Helpman, E., Krugman, P.R., 1985. Market structure and foreign trade. Cambridge, MA, MIT Press.

Kremer, M., 1993. The O-ring theory of economic development. Quarterly Journal of Economics 108(3), 551-575.

Krishna, K., Yavas, C., 2005. When trade hurts: Consumption indivisibilities and labor market distortions. Journal of International Economics 67(2), 413-427.

Krugman, P.R., 1980. Scale economies, product differentiation, and the pattern of trade. American Economic Review 70(5), 950-959. 
Sobel, J., 1992. How to count to one thousand. Economic Journal 102(410), 1-8.

\section{Appendix: Relaxing the symmetry of production functions}

In Section 3, Propositions 1 and 2 are obtained based on the assumption that the two countries have symmetric production functions. What if this is not the case? Suppose instead that the production functions (1) and (2) are replaced with the following, more general functions:

$$
\begin{array}{lll}
\text { Home: } & Q_{1 H}=A_{H} L_{1 H} & Q_{2 H}=B_{H} L_{2 H} \\
\text { Foreign: } & Q_{1 F}=A_{F} L_{1 F} & Q_{2 F}=B_{F} L_{2 F}
\end{array}
$$

Where $A_{H}, B_{H}, A_{F}$ and $B_{F}$ are technology parameters. Then, suppose that:

$$
A_{H}=3, \quad B_{H}=1, \quad A_{F}=9, \quad B_{F}=2
$$

With the other parameters as before. Now, both countries are better at producing good 1 than they are at producing good 2; that is, both countries have an "absolute $\operatorname{advantage"~}^{6}$ in producing good 1. However, Foreign now has a comparative advantage in producing good 1 , since $\left(A_{F} / B_{F}\right)>\left(A_{H} / B_{H}\right)$. Both countries satisfy Assumption 1, which means that, in autarky, both countries will specialise in good 1 , in which they have an "absolute advantage". When free trade is opened up between the two countries, both countries will remain specialised in good 1; that is, there will be no production of good 2, and no trade between the two countries. To see why, note that the free trade relative price will lie between the two countries' opportunity costs. Therefore, since Assumption 1 is satisfied, no consumer will want to consume any of good 2 given the free trade equilibrium price, and hence good 2 is never produced. Hence we have:

Proposition 5: If both countries have an "absolute advantage" in good 1, and Assumption 1 holds for both countries, opening up the two countries to free trade involves no international trade, and no change in the production bundle, consumption bundle, and welfare of the two countries.

\footnotetext{
6 "Absolute advantage" is in quotation marks, since Adam Smith's notion of absolute advantage relates to a country's technological superiority relative to another country, whereas our usage here relates to both countries' superiority in one good over another good.
} 